\title{
Oblique lonograms Automatic Scaling Algorithm OIASA application to the ionograms recorded by Ebro observatory ionosonde
}

\author{
Alessandro Ippolito ${ }^{1, *}$, David Altadill ${ }^{2}$, Carlo Scotto ${ }^{1}$ and Estefania Blanch ${ }^{2}$ \\ ${ }^{1}$ Istituto Nazionale di Geofisica e Vulcanologia, Via di Vigna Murata 605, Rome, Italy \\ 2 Observatori de l'Ebre, (OE), CSIC - Universitat Ramon Llull, Roquetes, Spain
}

Received 13 June 2017 / Accepted 6 December 2017

\begin{abstract}
The oblique ionograms automatic scaling algorithm (OIASA), developed at the INGV for the identification of trace of oblique ionograms, allows the determination of the maximum usable frequency (MUF) for communication between the transmitter and receiver, automatically rejecting poor quality ionograms. A test of the algorithm using data from a campaign of oblique soundings between Dourbes $\left(50.1^{\circ} \mathrm{N}, 4.6^{\circ} \mathrm{E}\right)$ and Roquetes $\left(40.8^{\circ} \mathrm{N}, 0.5^{\circ} \mathrm{E}\right)$ has been performed. Oblique soundings from three different campaigns have been studied, covering different geomagnetic conditions, in order to study the behavior of the autoscaling algorithm under quiet and perturbed geomagnetic periods. The reported results demonstrate that OIASA performance is not influenced by geomagnetic or ionospheric activity conditions. This demonstrates a satisfactory performance of the automatic scaling algorithm, even under different geomagnetic conditions, the potential application of OIASA as a near-real-time tool for ionospheric monitoring purposes, and its performance for tracking ionospheric effects caused by space weather events.
\end{abstract}

Keywords: ionosphere / oblique ionograms / automatic scaling / MUF

\section{Introduction}

The collection of ionospheric data coming from networks of vertical incidence ionosondes is the most used method to study the variable state of the ionosphere. Automatic interpretation of vertical ionograms used in operational ionospheric mapping has existed for some time. This offers the advantage to have real-time information of the state of the ionosphere. There are well-established techniques, which allow to automatically obtain the main physical ionospheric characteristics from a vertical incidence ionogram. These include the ARTIST method (Reinisch \& Huang, 1983; Gilbert \& Huang, 1988; Galkin et al., 2008) developed at the University of Massachusetts, Lowell, USA, and the Autoscala method developed at "Istituto Nazionale di Geofisica e Vulcanologia" (INGV), Italy (Scotto \& Pezzopane, 2002; Pezzopane \& Scotto, 2007; Scotto, 2009). Such computer programs are able to produce data that can be effectively integrated in real-time and short term forecasting models (Galkin et al., 2012). However, the information on the ionospheric parameters is strictly referred to the ionospheric region above the considered ionosonde, i.e. the transmitter and receiver of the radio signals are co-located.

Oblique ionospheric sounding extends this concept. In this case, the transmitter and receiver are generally located several

\footnotetext{
*Corresponding author: alessandro.ippolito@ingv.it
}

hundreds or thousands of kilometers apart, e.g. Warrington \& Stocker (2003), Ads et al. (2015). This way the instrumentation is able to study high frequency $(\mathrm{HF})$ radio signals propagation via the ionosphere under a variety of conditions and provide ionospheric estimates in between the transmitting and receiving sites. However, the interpretation of oblique ionograms is significantly more complex. The oblique ionograms automatic scaling algorithm (OIASA) for the automatic scaling of oblique ionograms (Ippolito et al., 2015, 2016) approaches the problem using the maximum contrast method. From an oblique ionogram it is possible to determine which frequencies are propagating between a given transmitter and receiver stations. Such information related to a particular HF propagation channel is very important because of the high variability of the ionospheric conditions, and the available frequencies for a considered radio link needs a constant update (Pijoan et al., 2014). The oblique ionograms also reveal the available communication bands and the gaps where no links can be established. An important advantage over vertical ionospheric sounding is the possibility to monitor the ionosphere across large otherwise inaccessible distances, like the oceans (Hervás et al., 2015).

This work aims at validating and assessing the performance of the OIASA, (Ippolito et al., 2015) for a particular radio-link between Dourbes (Belgium) and Roquetes (Spain). This will help the program of ionospheric observation and monitoring of the Ebro observatory (OE), but also proves its potential use for other similar radio links. 


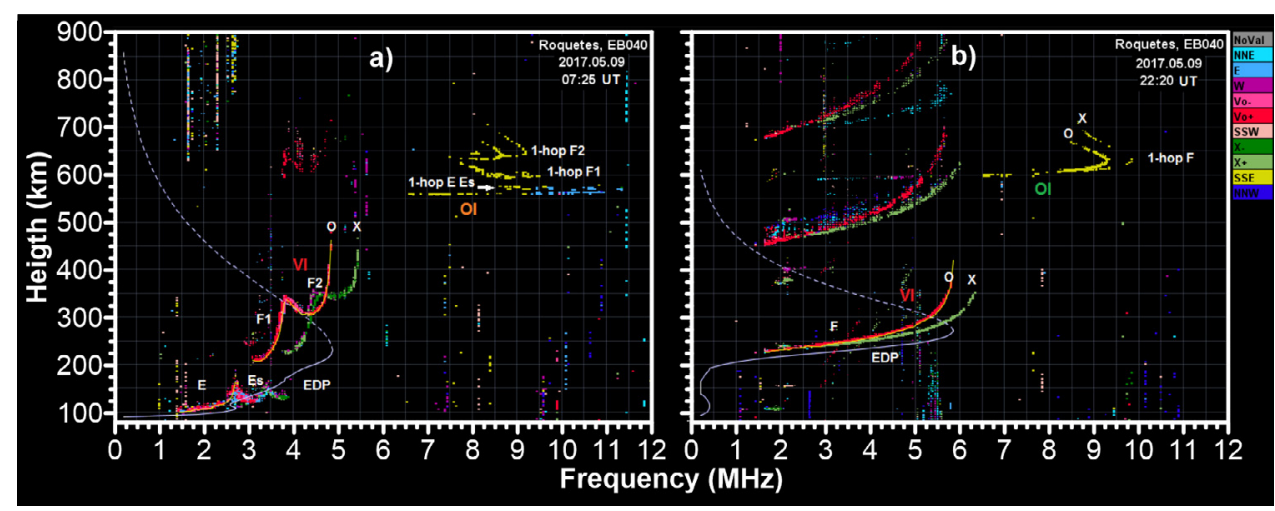

Fig. 1. Example of ionograms recorded at Ebro Observatory (Roquetes, EB040) for day time (left) and night time (right).

The automatic estimation of the maximum usable frequency (MUF) of this radio-link by OIASA for 1-hop F2 is analyzed for different seasons and ionospheric conditions. Results are compared to MUF measured by human experts to assess the OIASA goodness and to estimate its capability to track ionospheric variability conditions for quiet and disturbed conditions.

\section{Data}

OE operates a DPS4D ionosonde (EB040; $\left.40.8^{\circ} \mathrm{N}, 0.5^{\circ} \mathrm{E}\right)$ for ionospheric monitoring and research purposes (Reinisch et al., 2009). As part of OE ionospheric monitoring operation, their DPS4D makes vertical-incidence (VI) ionogram measurements every $5 \mathrm{~min}$. DPS4D OE ionograms exploit a method of mitigating in-band RF interference and the $h^{\prime}(f)$ precision ranging technique (Reinisch et al., 2008). This make possible to shorten the ionogram running time to few of seconds with low power transmission and with an accuracy better than $1 \mathrm{~km}$. The DPS4D runs the new ARTIST-5 ionogram autoscaling software (Galkin et al., 2008), which provides in real time the required data for assimilation in ionospheric models (Galkin et al., 2012), especially the IRI model (Bilitza et al., 2017). OE DPS4D operates with identical schedule and programs as other European DPS4Ds do. This enables to collect their own VI echoes, but also oblique-incidence (OI) signals from neighboring stations. Figure 1 illustrates two ionogram examples recorded at OE with OI signal transmitted by the DPS4D at Dourbes, Belgium (DB049; $\left.50.1^{\circ} \mathrm{N}, 4.6^{\circ} \mathrm{E}\right)$. The traces recorded by VI sounding corresponding to the ionospheric layers E, Es, F1 and F2 observed in day time ionograms are indicated in the Figure 1 (left) as well as the estimated electron density profile. Figure 1 left shows also the OI traces and it observes 1-hop echoes of E, Es, F1 and F2 layers. Figure 1b shows a typical night time ionogram where the $\mathrm{F}$ region is only present. Note that ionograms distinguish the ordinary $(\mathrm{O})$ and extraordinary $(\mathrm{X})$ ray. Normal operation of OE VI sounding measurements distinguish two schedules: day-time (DT) and night-time (NT). DT ionograms scans frequencies from $1.0 \mathrm{MHz}$ to $15.6 \mathrm{MHz}$ at $50 \mathrm{kHz}$ steps whereas NT ionograms scan from $1.0 \mathrm{MHz}$ to $11 \mathrm{MHz}$ in $50 \mathrm{kHz}$ steps. DT and NT ionograms are programmed according to current seasonal conditions adjusting periodically the DT and NT time settings according to length of day; i.e., winter DT (NT) ionograms run from 7:30 to $16: 30 \mathrm{UT}(16: 30$ to $7: 30 \mathrm{UT})$ whereas summer DT (NT) ionograms run from $6: 15$ to $22: 00 \mathrm{UT}(22: 00$ to $6: 15 \mathrm{UT})$.

VI signals on ionograms provide information of the ionospheric characteristics over the measuring site. OI signals on ionograms can provide information of the ionospheric characteristics at the reflection region of the radio link between distant sites. However, the large radiation beam-width of the DPS4D transmit antenna means that DPS4D usually launches multiple rays that can propagate to the receiver using different ionospheric propagation modes; e.g. 1F2 (i.e., 1-hop F2 layer reflection), $2 \mathrm{~F} 2,1 \mathrm{~F} 1,1 \mathrm{E}, 2 \mathrm{E}, 1 \mathrm{Es}$, etc. Considering the $\mathrm{OI}$ signal of the single hop propagation and that the OI signal reflects in the middle between transmitting (Tx) and receiving $(\mathrm{Rx})$ site, one can estimate ionospheric characteristics using simple formulation (Breit \& Tuve, 1926). Therefore, analyzing the OI signals transmitted in Dourbes (Tx) and received in Roquetes ( $\mathrm{Rx})$, one can estimate ionospheric characteristics in the middle of France, i.e. close to Saint-Exupéry-les-Roches $\left(45.5^{\circ} \mathrm{N}, 3.4^{\circ} \mathrm{E}\right)$.

To some extent, it is easy to distinguish OI signals from VI signals in the ionograms of EB040 under quiet ionospheric conditions; i.e., when only regular ionospheric layers are developed (Fig. 2a, e, f). The latter is also possible for ionograms with presence of sporadic E-layer echoes if these do not hide or overlap with upper layers echoes (Fig. 2b). However, a more challenging task is to distinguish OI signals under disturbed ionospheric conditions and consequently to estimate a realistic MUF. Such a disturbed condition can result from the presence of strong sporadic $E$ that hide signals of upper layers or whose multi Es modes can overlap OI F2 layer echoes (Fig. 2c, i). Geomagnetic storms can also complicate the task due to both negative and positive ionospheric effects. Negative ionospheric storms can result in a $\mathrm{G}$ condition, where F1 layer density is larger than F2 layer density and misinterpret the real 1F2 signal we are detecting (Fig. 2g). Negative storms can result in overlapping OI echo with VI echo if the negative ionospheric effect is large enough at the reflection point compared to the effect at receiving site (Fig. 2h). Positive ionospheric effects can also disturb automatic estimation of MUF, especially when such effects are significant enough that make signal echoes to extend beyond the ionogram scanning limits (Fig. 2d) therefore making it impossible to measure the MUF. Ionospheric storms can result in additional stratification of the ionosphere (Fig. 2j) posing additional difficulties to interpret OI signals. Other effects can be caused by ionospheric 

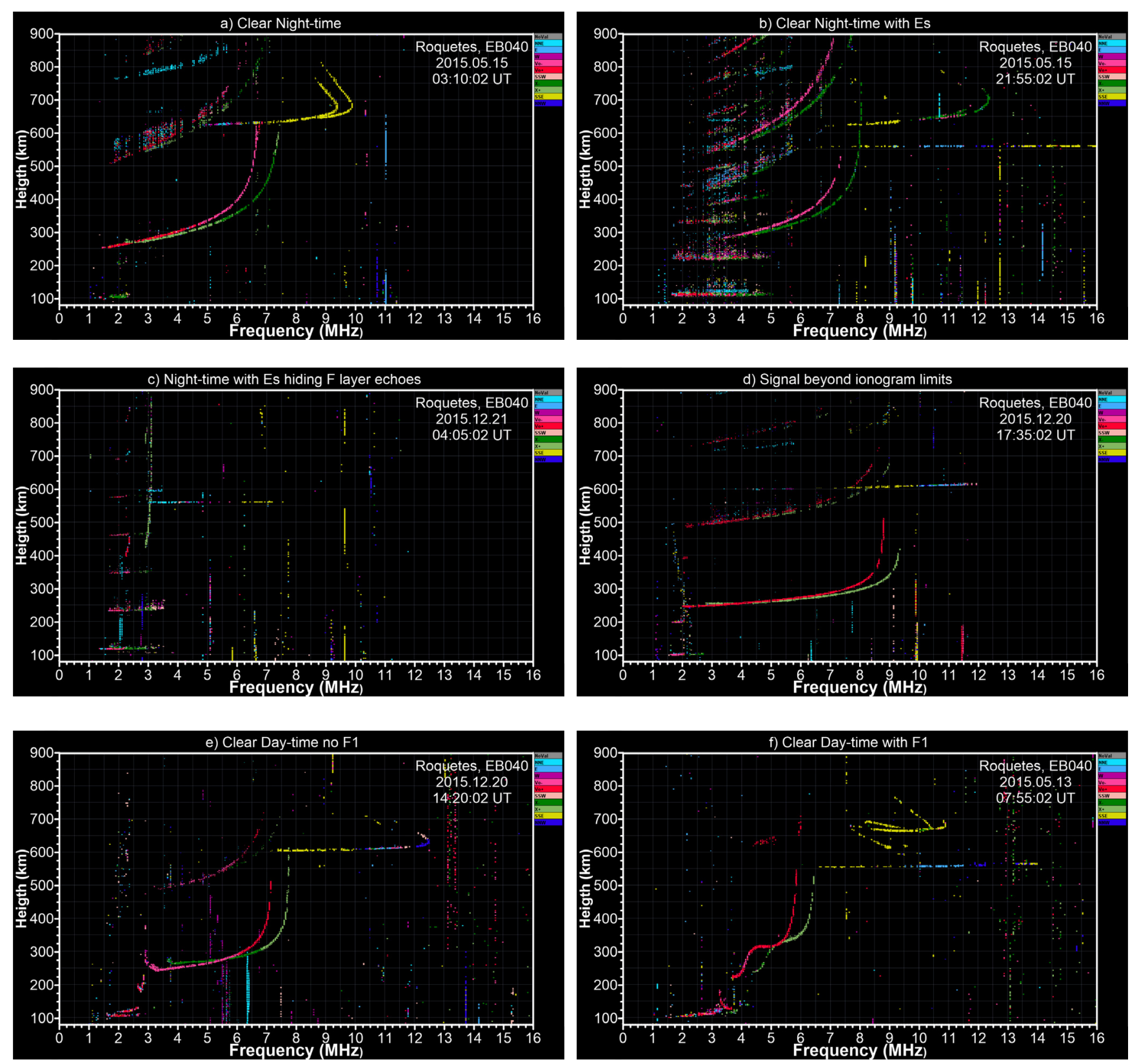

Fig. 2. (a-1). Example of ionograms recorded at Ebro Observatory (EB040 station) in different ionospheric conditions as indicated in the legends.

irregularities as traveling ionospheric disturbance (TIDs) passages, that might originate from by different sources (Hocke \& Schlegel, 1996) and among them it can be launched from auroral regions during geomagnetic disturbed periods (Prölss \& Očko, 2000). TIDs observed in VI echoes produces splitting of signal (Fig. 2k) and hock shaped (Fig. 21) of the ionogram traces that can be misinterpreted as addition ionospheric stratification in the OI signal traces.

A systematic analysis has been conducted of the ionospheric OI signals recorded in the ionograms of the EB040.
These ionograms contain the OI signals propagated through the approximately $1080 \mathrm{~km}$ radio link and synchronized to a transmitter in Dourbes (DB049). The OIASA algorithm (Ippolito et al., 2015) has been applied to the above mentioned ionograms to estimate the MUF for 1-F2 hop of the radio link for over 1485 ionograms. The ionograms were recorded under different seasonal, local time and geomagnetic activity conditions. Results of MUF estimated by OIASA are compared with MUF measured by human experts and confirm the goodness of OIASA in estimating MUF. 

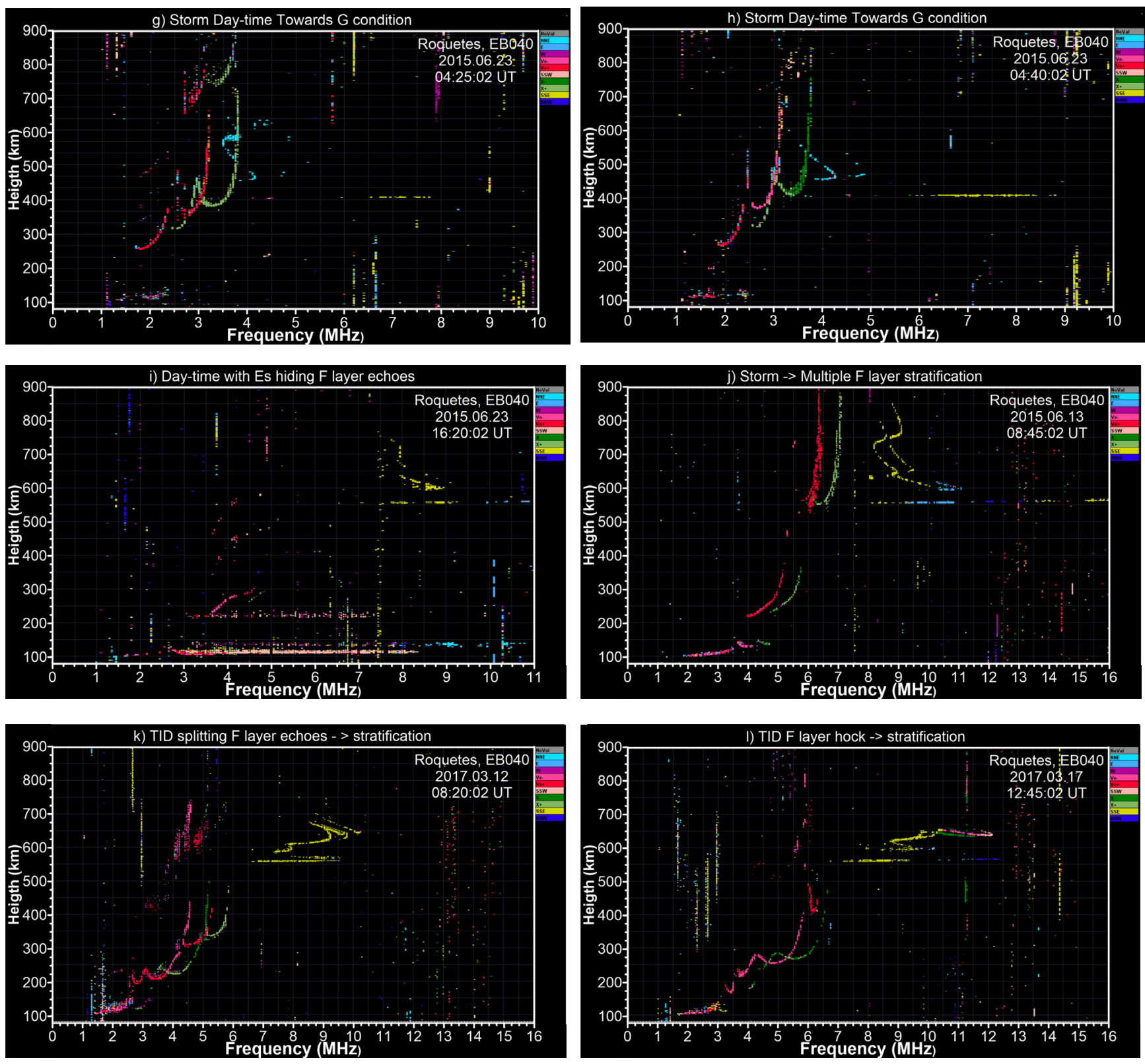

Fig. 2. (Continued)

\section{Methodology: the OIASA algorithm for the automatic scaling of oblique ionograms}

The OIASA algorithm (Ippolito et al., 2015, 2016) for the automatic scaling of oblique ionograms approaches the problem of the recognition of the oblique ionogram traces, using the maximum contrast method. As a first step, the row data files of the ionospheric sounding produced by the EB040 have been analyzed, and the ionograms have been stored in a matrix form, having $\mathrm{m}$ rows and $\mathrm{n}$ columns, as defined by the following formulas:

and

$$
m=\operatorname{int}\left[\frac{t_{f}-t_{0}}{\Delta_{t}}\right]+1
$$

$$
n=\operatorname{int}\left[\frac{f_{f}-f_{0}}{\Delta_{f}}\right]+1 \text {, }
$$

$t_{f}$ and $t_{0}$ in equation (1) refer respectively to the upper and lower limits of the time of measurement of the recorded ionograms and $\Delta_{t}$ refers to the time resolution of the measurement. Note that the vertical axis in the ionograms

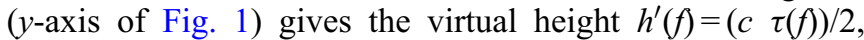
where $c$ is the free-space speed of light, and $\tau$ is the time of flight of the radio pulses. $f_{f}$ and $f_{0}$, in equation (2) are the final and initial frequencies scanned in the ionogram measurement respectively, and $\Delta_{f}$ refers to the coarse frequency step of the ionogram measurement. In general, $t_{0}$ and $\Delta_{t}$ are fixed values depending on the design of the 

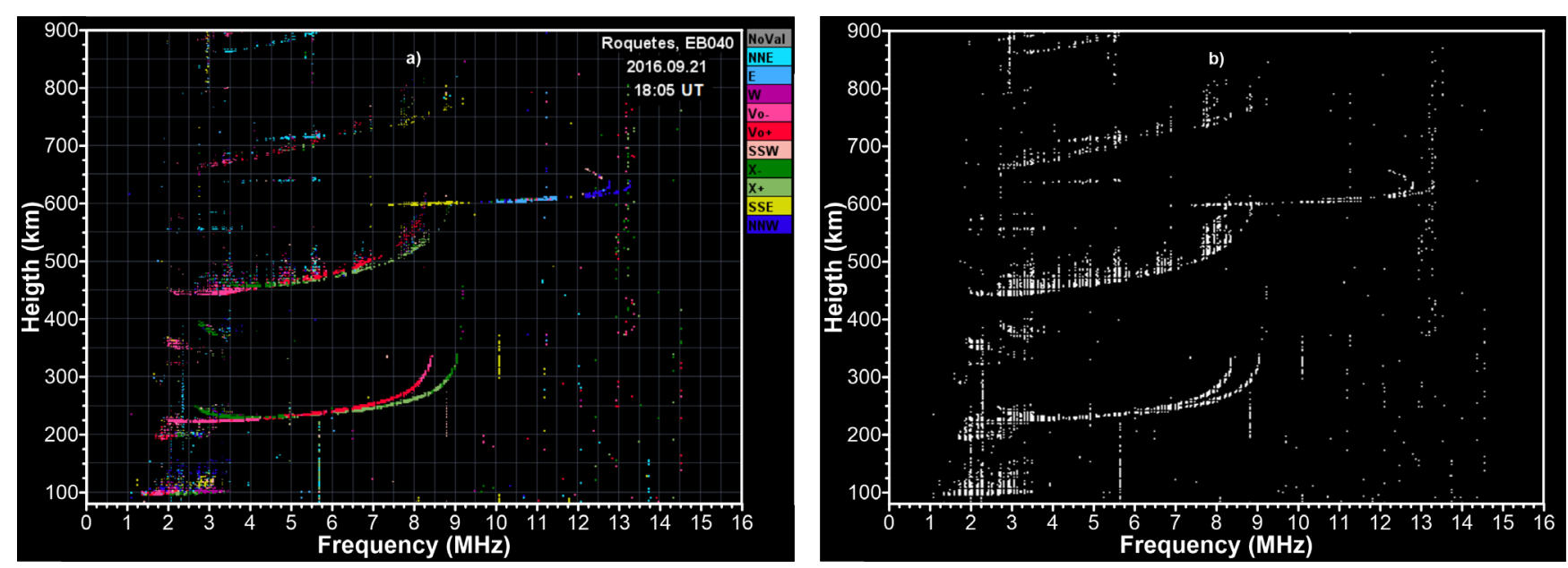

Fig. 3. Ionogram representation of the measurement recorded on 21/09/2016 at 18:05 universal time (UT) by the EB040 DPS4D. See text for details.

ionosonde. Figure 3 shows as example the ionogram registered on 21/09/2016 at 18:05 universal time. Panel (a) represents the plot of the ionogram data file provided by the EB040 DPS4D, and panel (b) refers to the matrix representation of the same ionogram but according to equations (1) and (2).

In OIASA algorithm, two branch of a parabola, $s_{\text {ord }}$ and $s_{\text {ext }}$, are empirically defined, to fit the typical shapes of the ordinary and extraordinary traces of the oblique ionogram resulting from a single reflection in the $\mathrm{F} 2$ region. Each branch of parabola is defined by a set of integer pairs $t, f$ where $t$ is associated to the time elapsed between transmission and reception and $f$ is associated to the frequency of the signal. The analytical equations of these curves are:

$$
\begin{gathered}
f_{\text {ord }}(t)=\operatorname{int}\left[A_{\text {ord }} \cdot t^{2}+B_{\text {ord }} \cdot t+C_{\text {ord }}\right], \\
f_{\text {ext }}(t)=\operatorname{int}\left[A_{\text {ext }} \cdot t^{2}+B_{\text {ext }} \cdot t+C_{\text {ext }}\right],
\end{gathered}
$$

for the ordinary and extraordinary trace of the oblique ionogram, respectively.

The coefficients $A_{\text {ord }}, B_{\text {ord }}$, and $C_{\text {ord }}$ are computed with the requirement that the parabola has vertex in $\left(f_{v_{\text {ord }}}, \mathrm{t}_{v_{\text {ord }}}\right)$, and width in $f_{v_{-} \text {ord }}-\delta \mathrm{f}_{-}$ord equal to $\delta t_{\text {ord }}$. This is obtained by setting:

$$
\begin{aligned}
& A_{\text {ord }}=-\frac{\left(\delta f_{-o r d}-f_{v_{-o r d}}\right)}{\delta t_{-o r d}}-\frac{f_{v_{-} \text {ord }}}{\delta t_{-} \text {ord }}{ }^{2},
\end{aligned}
$$

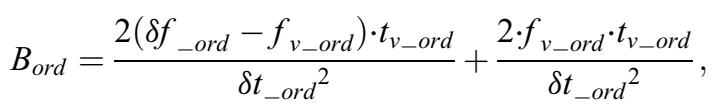

$$
\begin{aligned}
& C_{\text {ord }}=-\frac{\left(\delta f_{-o r d}-f_{v_{-} \text {ord }}\right) \cdot t_{v_{-} \text {ord }}{ }^{2}}{\delta t_{-o r d}}
\end{aligned}
$$

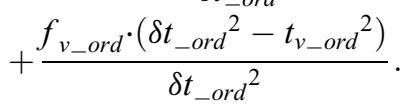

It is necessary to consider only integer pairs $\left(f_{\text {ord }}, t_{-}\right.$ord $)$ (and $\left.\left(f_{- \text {ext }}, t_{\text {ext }}\right)\right)$ because the point $P \equiv\left(f_{\text {ord }}, t_{\text {ord }}\right)$ (and $\left.P \equiv\left(f_{- \text {ext }}, t_{\text {_ext }}\right)\right)$ shall be compared to the entries of the matrix representing the ionogram. In equations (3) and (4) $t$ varies within the interval $\left[t \_\right.$ord min,$t \_o r d$ max $]$. The limits $t \_o r d \_m i n$ and $t_{-}$ord_max are chosen in such a way that $f$ lies within the following limits: $f_{v \_o r d}-\delta f_{\text {ord }} \leq f \leq f_{v \_ \text {ord }}$ for the ordinary trace, and $f_{v \text { ext }}-\delta f_{\text {ext }} \leq f \leq f_{v \text { ext }}$ for the extraordinary trace.

In these expressions $f_{v \_ \text {ord }}$ and $t_{v \_o r d}\left(f_{v \_ \text {ext }}\right.$ and $\left.t_{v \_ \text {ext }}\right)$ represent the coordinates of the vertex of the parabola fitting the ordinary (extraordinary) trace. $\delta f_{\text {ord }}\left(\delta f_{\text {ext }}\right)$ represents the range of $f$ in which the parabola fitting the ordinary (extraordinary) trace is computed. $\delta t_{-}$ord $\left(\delta t_{-}\right.$ext $)$represent the half width of the parabola corresponding to abscissa $f_{v \_o r d}-\delta f \_$ord $\left(f_{v \_ \text {ext }}-\delta f \_\right.$ext $)$.

The curves $s_{\text {ord }}$ and $s_{\text {ext }}$ are slid across the ionogram, $f_{v_{-} \text {ord }}$ varies in this way from $\delta f_{\text {ord }}$ to $n-\Delta f_{\text {ord-ext }}$, while $t_{v \_ \text {ord }}$ varies from $\delta_{t \text { ord }}$ to $m$, and $m$ and $n$ are defined by (1) and (2).

$\Delta f_{\text {ord-ext }}$ is a fixed value taking into account the ordinaryextraordinary magnetoionic frequency splitting, which is related to the giro frequency $f b$ associated with the considered radio link: $\Delta f_{\text {ord-ext }}=\operatorname{int}[0.5 \cdot f b / \Delta f]$.

A similar range of variation is defined for $f_{v \text { ext }}$ and $t_{v \_ \text {ext }}$. Furthermore, varying the parameters $\mathrm{A}, \mathrm{B}$ and $\mathrm{C}$ in equations (3) and (4), and thus causing $s_{\text {ord }}$ and $s_{\text {ext }}$ to change shape, while maintaining consistency with the typical oblique ionogram trace shape, results in moving the curves throughout the ionogram. This procedure is described by Ippolito et al. (2015). In this way, for each pair of curves, the local contrast $C\left(f_{v \_ \text {ord }}\right.$, $\left.\delta f_{\text {ord }}, t_{v_{\text {orord }}}, \delta t_{\text {oord }}, f_{v_{\text {_ext }}}, \delta f_{\text {ext }}, t_{v_{\text {_ext }}}, \delta t_{\text {ext }}\right)$ with the recorded ionogram traces is calculated, as $C^{-}=C_{\text {ord }}+C_{\text {ext }}$, making allowance for both the number of matched points and their amplitude. Note that $f_{v \text { ext }}$ is not independent as it is related to $f_{v \text { ord }}$ assuming $f_{v \text { ext }}=f_{v \text { ord }}+\Delta f_{\text {ord-ext }}$. Besides are assumed as constant $\delta f_{-}$ord $=\overline{3} 0$ and $\delta f_{\text {ext }}=30$. The algorithm to compute $C$ is similar to the one used by Autoscala to detect the F2 layer trace in vertical ionograms and it is based on the sum of the single contrast elements (SEC) according to the following (6a) and (6b): 

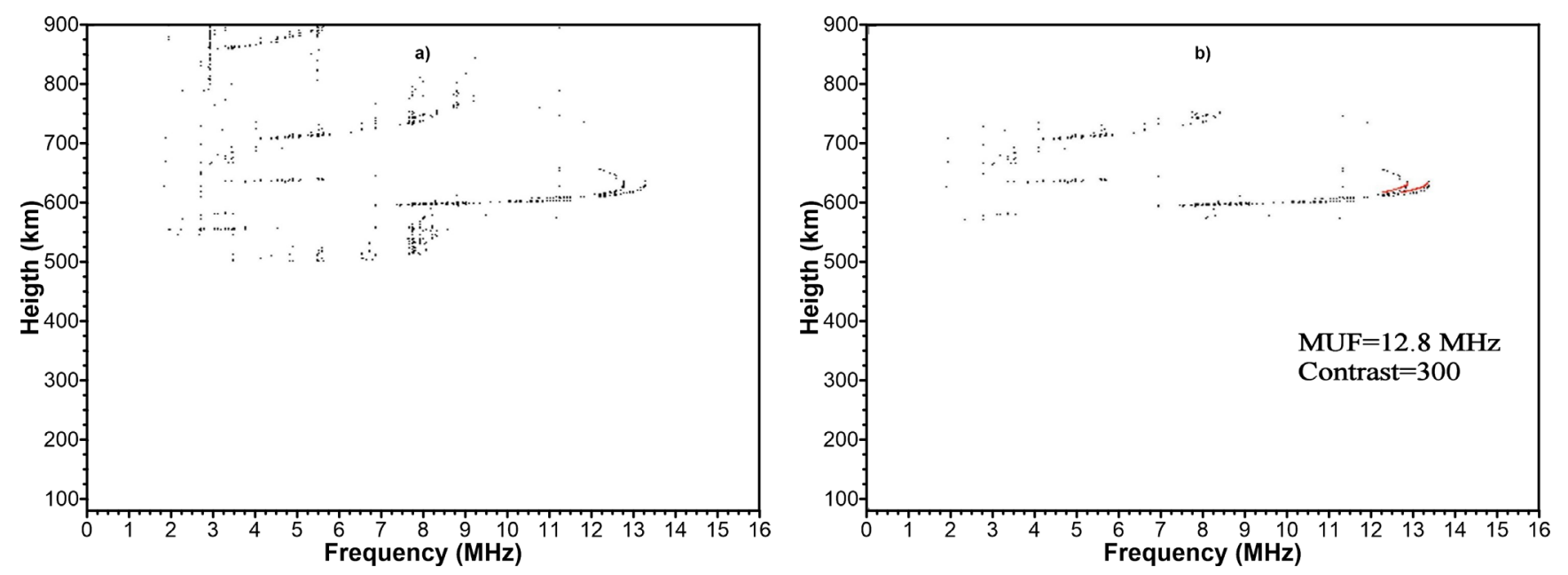

Fig. 4. Panel (a) shows the matrix representation of the ionogram registered on 21/09/2016 at 18:05 UT, after filtering out the echoes with $\mathrm{h}^{\prime}<500 \mathrm{~km}$ and with $\vartheta<30^{\circ}$. Panel (b) represents the same oblique ionogram automatically scaled by OIASA, after a filtering procedure to reduce the image noise.

$$
\begin{aligned}
C_{\text {ord }} & =\sum_{t=t_{-} \text {ord_min }}^{t=t_{-} \text {ord_max }} \operatorname{Sin} C\left[f_{- \text {ord }}(t), t\right], \\
C_{\text {ext }} & =\sum_{t=t t_{-} \text {ext_min }}^{t=t_{-} \text {ext_max }} \operatorname{SEC}\left[f_{- \text {ext }}(t), t\right] .
\end{aligned}
$$

The SEC is defined by the expression (6) in Cesaroni et al. (2013).

The pair of empirical curves $s_{\text {ord }}$ and $s_{\text {ext }}$ characterized by the maximum value of $C$, called $C_{\max }$, is then selected as representative of the traces shape of the considered oblique ionogram. The MUF for the specific considered ionogram, is inferred from the vertex point of the $s_{\text {ord }}$ parabola, $V_{\text {ord }}$, of coordinates $\left(f_{v_{\text {ord }}}, t_{v_{\text {ord }}}\right)$. Therefore MUF is the frequency associated to $\overline{f_{v} \text { ord }}=\operatorname{int}\left[\left(M U F-f_{\mathrm{o}}\right) / \Delta f\right]$. The contrast method here used for the calculation of the correlation between the empirical curves and the elements of the matrix that constitute the oblique ionogram, also provides a criterion for discarding ionograms that lack sufficient information. Indeed, only if $C_{\max }$ is larger than a fixed threshold $C_{t}$, the resulting curves, are considered representative of the traces of a given oblique sounding. Otherwise, the ionogram is considered to lack sufficient information and then discarded. In this case, no MUF value is provided as output.

\section{Results of OIASA algorithm applied to OE oblique soundings}

The automatic scaling algorithm OIASA has been applied to 1485 oblique ionograms produced by the $\mathrm{OE}$, related to the radio link of $1058 \mathrm{~km}$ between the stations of Roquetes (EB040) and Dourbes (DB049). Three different periods have been considered in order to cover different geomagnetic conditions and to study the behaviour of the algorithm for both quiet and disturbed ionospheric conditions. Have been studied a number of 576 hourly ionograms from an ionospheric oblique sounding campaign from $02 / 05 / 2015$ to $24 / 05 / 205$, 549 hourly ionograms from a campaign conducted between 26/09/2015 and 18/10/2015, and 360 oblique ionograms taken every two hours during September, 2016. OIASA results are compared with MUF interpretation by an expert operator. The procedure performed by OIASA for the automatic scaling of oblique ionograms is based on an image recognition technique. That is why it becomes crucial to isolate the oblique sounding traces from the rest of the information carried by the OE's ionograms.

To filter out the undesired information we discard all signals from echoes with a virtual height $\left(h^{\prime}\right)$ lower than $500 \mathrm{~km}$. Note that it is unlikely to receive $\mathrm{F}$ region echoes with such a $h^{\prime}$ due to the geometry of the radio link because the expected $h^{\prime}$ for a 1-hop reflection in the F-region for this particular radio link is larger than $550 \mathrm{~km}$. We also take advantage of the zenith angle information of the radio signals received by the DPS4D at OE and filter out all echoes received with a zenith angle lower than $30^{\circ}$. This way we remove the assumed "near vertical" echoes and focus on signals of the ionogram with significant oblique angle of arrival at $\mathrm{OE}$ DPS4D site. Note that the expected zenith angle of arrival $(\vartheta)$ for a 1-hop reflection in the F-region for this particular radio link is about 50 degrees or larger. Figure 4a depicts an example of the matrix representation of the ionogram recorded on 21/ 09/2016 at 18:05 UT, once the above filtering process has been applied. In addition, we apply the algorithm described by Ippolito et al. $(2015,2016)$ to filter the image noise, resulting in a cleaner image of the matrix representation of the same ionogram (Fig. 4b).

After the above filtering processes of the ionogram, OIASA calculates the local correlation $C\left(f_{v_{\text {ord }}}, \delta_{f_{\text {ord }}}, t_{v_{-} \text {ord }}\right.$, $\left.\delta_{t_{\text {ord }}}, f_{v_{\text {ext }}}, \delta_{f_{\text {_ext }}}, t_{v_{\text {_ext }}}, \delta_{t_{\text {_ext }}}\right)$ for each pair of curves $S_{\text {ord }}$ and $S_{\text {ext }}$ with the recorded ionogram. Finally OIASA selects the pair of curves $S_{\text {ord }}$ and $S_{\text {ext }}$ that have the maximum value of $C$ $\left(C_{\max }\right)$ as representative curves of the oblique ionogram traces. Panel (b) of Figure 4 shows the $S_{\text {ord }}$ and $S_{\text {ext }}$ curves estimated 
Table 1. Autoscaling results of the oblique ionograms data set of 576 ionograms recorded between May 2, 2015 and May 24, 2015. Accurate cases $\left(M U F_{\text {OISA }}-M U F_{\text {Operator }} \leq 0.5 \mathrm{MHz}\right)$ are a subset of acceptable cases $\left(M U F_{\text {OISA- }} M U F_{\text {Operator }} \leq 1.5 \mathrm{MHz}\right)$.

\begin{tabular}{|c|c|c|c|c|}
\hline & \multicolumn{2}{|c|}{ Scaled by OIASA } & \multicolumn{2}{|c|}{ Discarded by OIASA } \\
\hline & $\begin{array}{l}\text { No. of } \\
\text { cases }\end{array}$ & $\%$ & $\begin{array}{l}\text { No. of } \\
\text { cases }\end{array}$ & $\%$ \\
\hline $\begin{array}{l}\text { The Operator did not } \\
\text { scale the MUF }\end{array}$ & 22 & 4.0 & 14 & 77.8 \\
\hline \multirow{4}{*}{$\begin{array}{l}\text { The operator scaled the } \\
\text { MUF } \\
\text { Total }\end{array}$} & 536 & 96.0 & 4 & 22.2 \\
\hline & 558 & - & 18 & - \\
\hline & \multicolumn{4}{|c|}{ Scaled by OIASA and the operator } \\
\hline & \multicolumn{2}{|c|}{ No. of cases } & \multicolumn{2}{|c|}{$\%$} \\
\hline Accurate & \multicolumn{2}{|l|}{166} & \multicolumn{2}{|c|}{31.0} \\
\hline $\begin{array}{l}\text { Acceptable (including } \\
\text { accurate) }\end{array}$ & \multicolumn{2}{|l|}{367} & \multicolumn{2}{|c|}{68.5} \\
\hline Poor & \multicolumn{2}{|l|}{169} & \multicolumn{2}{|c|}{31.5} \\
\hline Total & \multicolumn{2}{|l|}{536} & \multicolumn{2}{|c|}{-} \\
\hline
\end{tabular}

for the ionogram example corresponding to the oblique sounding recorded on 21/09/2016 at 18:05 UT.

A preliminary test of the OIASA algorithm has been conducted on a database of 549 ionograms recorded by the DPS4D of OE, in order to evaluate the best value of the contrast threshold $C_{t}$. To do so, several runs of OIASA with different values of contrast threshold $C_{t}$, have been carried out for the same ionogram data set. The test allowed to fix a threshold value of $C_{t}=200$. This threshold value provides the best performance when the results are compared with the ones given by manual scaling. Hereafter, all the oblique ionograms to be scaled automatically by OIASA algorithm that are characterized by a $C_{\max }$ lower then $C_{t}$, are considered to lack of sufficient information and therefore automatically discarded. The performance of the autoscaling algorithm changes depending on the quality of the analyzed ionograms and poor quality ionograms might be misinterpreted. This in turn results to wrong estimation of ionospheric characteristic which would be responsible for an unreasonable behaviour of assimilative models (Galkin et al., 2012). That is why it is preferred to discard a priory the ionograms with poor information $\left(C_{t}<200\right)$ than provide wrong automatic measurements.

To distinguish the quality of the automatic estimates of OIASA, we qualify the MUF values provided by the autoscaling algorithm as accurate, when the MUF value of the OIASA estimate deviates less than $0.5 \mathrm{MHz}$ from the MUF value provided by the operator, acceptable, when this value deviates less than $1.5 \mathrm{MHz}$ from the operator's MUF measurement, and poor when it deviates more than 1.5 MHz. This range of intervals of deviation are chosen in accordance to the limits identified by the URSI standards, as defined by Piggott \& Rawer (1972). According to this definition "Accurate" cases are included in "Acceptable" cases. This criterion has been used to build up Tables $(1 \mathrm{~b}-5 \mathrm{~b})$ where the percentage of acceptable and poor sum up to $100 \%$, this
Table 2. Autoscaling results of the oblique ionograms data set of 360 ionograms recorded between September 1, 2016 and September 30, 2016. Accurate cases $\left(M U F_{\text {OISA }}-M U F_{\text {Operator }} \leq 0.5 \mathrm{MHz}\right)$ are a subset of acceptable cases $\left(M U F_{\text {OISA }}-M U F_{\text {Operator }} \leq 1.5 \mathrm{MHz}\right)$.

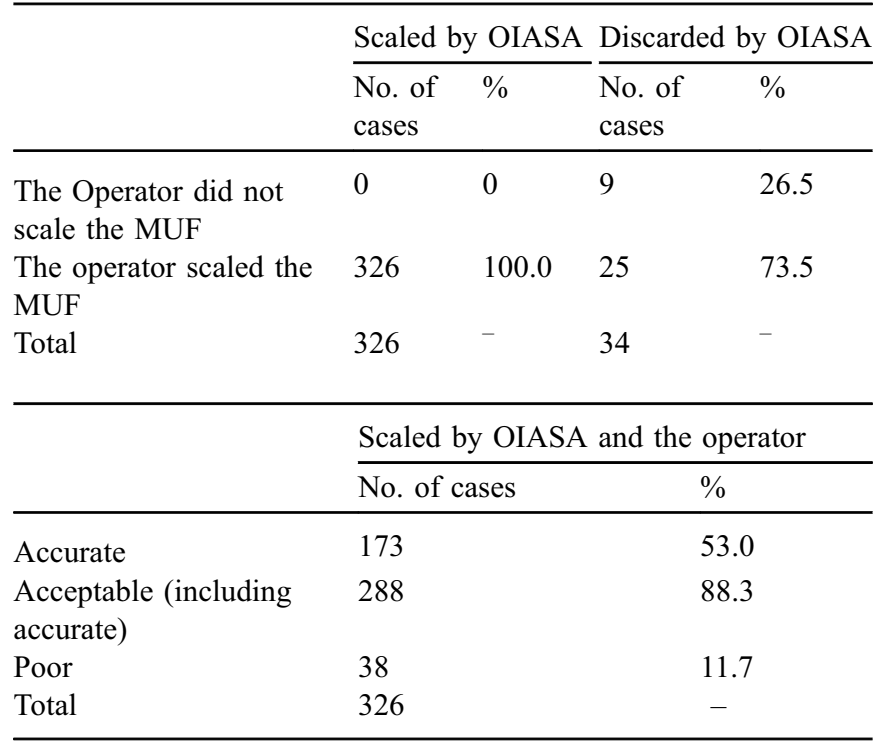

because the percentage of accurate is included in the percentage of acceptable.

\subsection{Assessment of OIASA algorithm for long term oblique sounding campaign}

Tables $1 \mathrm{a}$ and $\mathrm{b}$ report a summary of the results of the OIASA application to 576 oblique ionograms registered between 2 and 24 May, 2015.

An expert operator scaled the whole ionograms of the considered dataset. He was able to scale the MUF value for 540 oblique ionograms out of the 576 ionograms of the dataset for this particular time interval, and he discarded 36 ionograms for which no clear OI trace was identified. Table 1a compares the number of ionograms scaled and discarded by OIASA algorithm with that scaled by expert, showing a good agreement between them. Indeed for $96 \%$ of the ionogram scaled by OIASA also the operator was able to scale a MUF value. However, $4 \%$ of the ionograms scaled by OIASA were not possible to measure MUF by human expert which can be attributed to a false MUF estimate. This means that the capabilities of the autoscaling algorithm are remarkable, as well as the OIASA capabilities in discarding ionograms that lack sufficient information. Table $1 \mathrm{~b}$ shows the quality of the scaling estimates by OIASA assuming the measurement of human expert as the true value. The results show that only $70 \%$ of the MUF values estimated by OIASA algorithm deviate less than $1.5 \mathrm{MHz}$ from the MUF value provided by the operator, i.e. MUF estimates by OIASA are within the URSI standards. However, we should notice that May is characterized by high occurrence of Es layer that often partly hide the signals of upper layers in the ionograms (e.g. Fig. 2c, i). Consequently the Es layer shorten the available frequency range of the oblique ionogram traces of the $\mathrm{F}$ region with 
Table 3. Autoscaling results of the oblique ionograms data set of 549 ionograms recorded between September 25, 2015 and October 18,2015 . Accurate cases $\left(M U F_{\text {OISA }}-M U F_{\text {Operator }} \leq 0.5 \mathrm{MHz}\right)$ are a subset of acceptable cases ( $\left.M U F_{\text {OISA }}-M U F_{\text {Operator }} \leq 1.5 \mathrm{MHz}\right)$.

\begin{tabular}{|c|c|c|c|c|}
\hline & \multicolumn{2}{|c|}{ Scaled by OIASA } & \multicolumn{2}{|c|}{ Discarded by OIASA } \\
\hline & $\begin{array}{l}\text { No. of } \\
\text { cases }\end{array}$ & $\%$ & $\begin{array}{l}\text { No. of } \\
\text { cases }\end{array}$ & $\%$ \\
\hline $\begin{array}{l}\text { The Operator did not } \\
\text { scale the MUF }\end{array}$ & 7 & 1.5 & 51 & 58.6 \\
\hline The operator scaled the & 455 & 98.5 & 36 & 41.4 \\
\hline \multirow[t]{3}{*}{ Total } & 462 & - & 87 & - \\
\hline & & \multicolumn{3}{|c|}{ Scaled by OIASA } \\
\hline & & \multicolumn{2}{|c|}{ No. of cases } & $\%$ \\
\hline \multicolumn{2}{|l|}{ Accurate } & \multicolumn{2}{|l|}{215} & 47.3 \\
\hline \multicolumn{2}{|c|}{ Acceptable (including accurate) } & \multicolumn{2}{|l|}{372} & 81.8 \\
\hline \multicolumn{2}{|c|}{ Poor } & \multicolumn{2}{|l|}{83} & 18.2 \\
\hline \multicolumn{2}{|l|}{ Total } & \multicolumn{2}{|l|}{455} & - \\
\hline
\end{tabular}

significant signal to allow the contrast method to obtain a reliable parabola to fit.

The results of comparison improve for estimates over ionogram datasets recorded in different seasons, when ionograms are characterized by a lower occurrence of Es layer. This can be seen from the results shown in Tables $2 \mathrm{a}$ and $\mathrm{b}$ that summarize the results of the OIASA application to 360 oblique ionograms registered between 1 and 30 September of 2016.

An expert operator was able to scale the MUF value for 351 oblique ionograms out of the 360 ionograms of the dataset (by $97 \%$ ) for this particular time interval. OIASA algorithm was able to estimate the MUF for 326 ionograms out of 351 scaled by the operator, providing $173(53.0 \%)$ accurate and 288 $(88.3 \%)$ acceptable estimate. This demonstrates a very good agreement between the MUF values estimated by OIASA and the corresponding given by the operator. The low $\%$ of poor quality estimates for September 2016 compared to May 2015 might be related to the fact that September has less Es layer occurrence compared to May, which in turn results to a better ionogram quality for scaling purposes. In this case, for all the ionograms scaled by OIASA, the operator was able to find a MUF value, and all the ionograms discarded by the operator are discarded by the OIASA algorithm too. A number of 25 ionograms, over 360 , were discarded by the autoscaling algorithm, while the operator was able to find a MUF value. This can be interpreted as an error of the program, but, in an automatic scaling procedure, is much more important to provide no wrong values as output than discard some information. In this case only the $7 \%$ of the scalable ionograms are discarded by OIASA, but no wrong MUF estimation were provided as output by the algorithm.

A third oblique ionograms dataset has been analyzed, containing 549 oblique soundings registered by the DPS4D at $\mathrm{OE}$ at each hour of the day, from 26 September 2015 to 18 October 2015. The results of the OIASA performance
Table 4. Autoscaling results of the oblique ionograms data set of 24 ionograms recorded on October 7, 2015, when the Ap index had a value of 74, corresponding to disturbed geomagnetic conditions were recorded. Accurate cases $\left(M U F_{\text {OISA }}-M U F_{\text {Operator }} \leq 0.5 \mathrm{MHz}\right)$ are a subset of acceptable cases ( $\left.M U F_{\text {OISA }}-M U F_{\text {Operator }} \leq 1.5 \mathrm{MHz}\right)$.

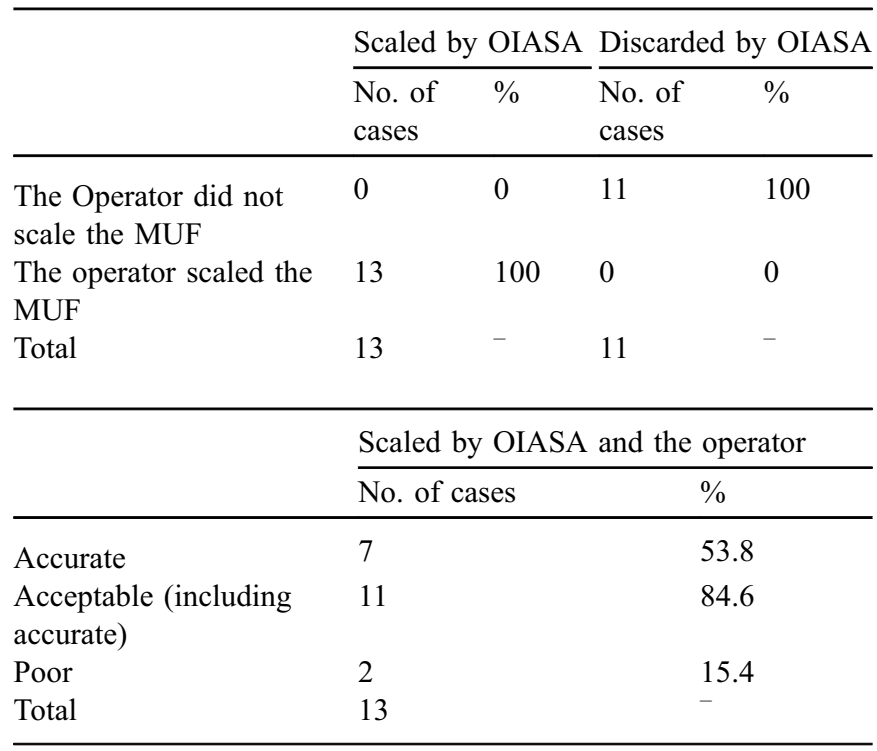

compared to the manual scaling, are reported in Tables $3 \mathrm{a}$ and $b$.

As shown in Table 3a, the operator was able to scale the MUF for 491 oblique ionograms out of 549. OIASA algorithm was able to estimate the MUF for 455 ionograms out of 491 scaled by the operator, providing $215(47.3 \%)$ accurate and $372(81.8 \%)$ acceptable. Again the good performance of the algorithm is shown, as only $18 \%$ of the results provided by OIASA can be considered to have a poor quality. The lower $\%$ of poor quality estimates for October 2015 compared to May 2015 might be related to the fact that October has less Es layer occurrence compared to May, which in turn results to a better ionogram quality for scaling purposes. However October 2015 reports larger geomagnetic activity compared to September 2016 , which can support the larger $\%$ of poor quality estimates of MUF for October 2015 in relation to September 2016.

\subsection{Capability of OIASA to monitor oblique sounding under geomagnetic disturbed conditions}

Two days of the considered time period, correspond to a magnetic storm, this provided the possibility to study the performance of the automatic scaling algorithm under perturbed geomagnetic and ionospheric conditions. Seventh and eighth October, 2015 are indeed characterized by an Ap index of 74 and 45, respectively, while Dst index dropped below $-110 \mathrm{nT}$ on October 7th. This means that an intense geomagnetic storm, according to Gonzalez \& Tsurutani (1987), has affected the Earth ionosphere these days, inducing ionospheric disturbances over Europe. Such disturbances can be observed by the trend of the AI index (Mielich \& Bremer, 2010) provided by the NOA at the DIAS web page (http://hertz2.space.noa.gr:8080/Latest 
Table 5. Autoscaling results of the oblique ionograms data set of 24 ionograms recorded on October 8, 2015, when the Ap index had a value of 45 , corresponding to disturbed geomagnetic conditions were recorded. Accurate cases $\left(M U F_{\text {OISA }}-M U F_{\text {Operator }} \leq 0.5 \mathrm{MHz}\right)$ are a subset of acceptable cases (MUF $\left.F_{\text {OISA }}-M U F_{\text {Operator }} \leq 1.5 \mathrm{MHz}\right)$.

\begin{tabular}{|c|c|c|c|c|}
\hline & \multicolumn{4}{|c|}{ Scaled by OIASA Discarded by OIASA } \\
\hline & $\begin{array}{l}\text { No. of } \\
\text { cases }\end{array}$ & $\%$ & $\begin{array}{l}\text { No. of } \\
\text { cases }\end{array}$ & $\%$ \\
\hline $\begin{array}{l}\text { The Operator did not } \\
\text { scale the MUF }\end{array}$ & 1 & 6.25 & 7 & 87.5 \\
\hline \multirow{4}{*}{$\begin{array}{l}\text { The operator scaled the } \\
\text { MUF } \\
\text { Total }\end{array}$} & 15 & 93.75 & 1 & 12.5 \\
\hline & 16 & - & 8 & - \\
\hline & \multicolumn{4}{|c|}{ Scaled by OIASA and the operator } \\
\hline & \multicolumn{2}{|c|}{ No. of cases } & \multicolumn{2}{|r|}{$\%$} \\
\hline Accurate & \multicolumn{2}{|l|}{10} & \multicolumn{2}{|r|}{66.7} \\
\hline $\begin{array}{l}\text { Acceptable (including } \\
\text { accurate) }\end{array}$ & \multicolumn{2}{|l|}{14} & \multicolumn{2}{|r|}{93.3} \\
\hline Poor & \multicolumn{2}{|l|}{1} & \multicolumn{2}{|r|}{6.7} \\
\hline Total & \multicolumn{2}{|l|}{15} & \multicolumn{2}{|r|}{-} \\
\hline
\end{tabular}

Dias2/loginPage.jsp). Since the values of AI index for these days are not available for the Ebro ionosonde, as reported on the DIAS web page we considered the trend of AI index related of two ionospheric stations of Rome (Italy) and Chilton (England). As described at the DIAS portal, an AI index within the range of \pm 25 describes a quiet ionospheric situation, ionospheric disturbed conditions are characterized by AI values that go from -25 to -50 and from 25 to 50 . For AI greater than 50 or lower than -50 we are in an extremely disturbed condition.

Tables $4 \mathrm{a}$ and $\mathrm{b}$ report a summary of the results of the MUF scaling by OIASA algorithm of the 24 oblique hourly ionograms recorded on 7 of October 2015. These tables show a very good agreement between the results of the automatic and manual scaling of the ionograms recorded on October 7 2015. All the ionograms discarded by the operator are discarded by OIASA as well. Furthermore, concerning the quality of the scaling, Table $4 \mathrm{~b}$ shows that by $85 \%$ of the MUF estimates lies into the URSI standards and only $15 \%$ can be considered to have a poor quality.

Similar good results can be deduced from Tables $5 \mathrm{a}$ and $\mathrm{b}$ that summarize the scaling results of the oblique ionograms recorded on October 82015 . Indeed there is only 1 case of wrong MUF estimation and more than $93 \%$ of the MUF values estimated by OIASA deviates less than $1.5 \mathrm{MHz}$ from the MUF value given by the operator.

The results of the comparison between automatic scaling and manual scaling of the ionograms recorded on 7 and 8 of October 2015, are plotted in Figure 5. The good agreement between the MUF values estimated by OIASA and the ones measured by the human operator can be seen. The error bars indicate the range of $\pm 1.5 \mathrm{MHz}$ according to the URSI standards. The black line on the lower panel of Figure 5, represents the average manual MUF values, considering a week before and a week after the two ionospheric disturbed

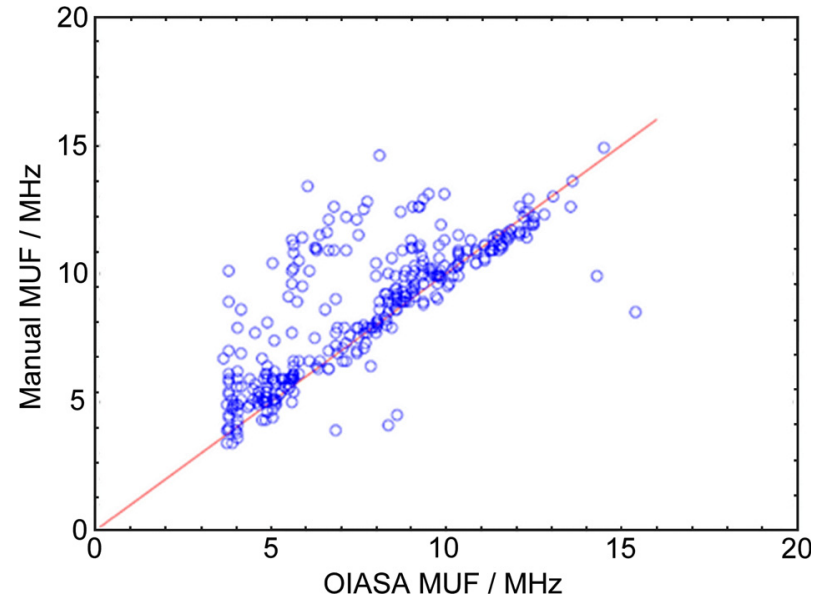

Fig. 5. Scatter plot of MUF values estimated by OIASA plotted vs MUF values provided by the expert. The comparison with the function $y=x$, shows a good behavior of the autoscaled algorithm in terms of detecting the MUF.

days. The upper panel of the same figure depicts the trend of the AI index over the two ionospheric stations of Rome and Chilton, for the considered time interval. It can be clearly seen how the many of the disturbed hours correspond to a number of bad quality ionograms, which are discarded both by OIASA and the operator, meaning that it is not possible to measure MUF. Note that for the time interval with measurements and when AI index indicates ionospheric disturbance, a negative effect is observed in both MUF measured by operator and estimated by OIASA. This proves the capability to monitor ionospheric effects caused by geomagnetic disturbances by the OIASA algorithm and the possibility to use it as a near-real-time tool for ionospheric monitoring purposes. A correspondence between the lack of scaled ionograms and the main disturbed hours of the considered days can be clearly seen. Also, it is worth noticing the good agreement between OIASA estimates of MUF and the measurements by operator as well as for discarding the ionograms recorded in most disturbed hours.

\section{Summary and conclusions}

The INGV OIASA algorithm, for the automatic scaling of the traces of an oblique ionogram, has been applied to three different datasets of oblique ionograms recorded by the ionospheric sounder DPS4D of the OE (EB040), Spain. The oblique signal on EB040 ionograms is transmitted from DPS4D of Dourbes (DB049) which is located $1080 \mathrm{~km}$ northeast from EB040. Both ionospheric sounders EB040 and DB049 operate in a synchronized modes for ionospheric monitoring purposes. A total number of 1485 oblique soundings have been analyzed and OIASA algorithm has been applied in order to scale automatically the 1-hop F region MUF. The data sets encompass different seasonal and geomagnetic activity conditions and the analysis made possible to evaluate the performance of OIASA for monitoring ionospheric characteristics from oblique incidence radio soundings. 


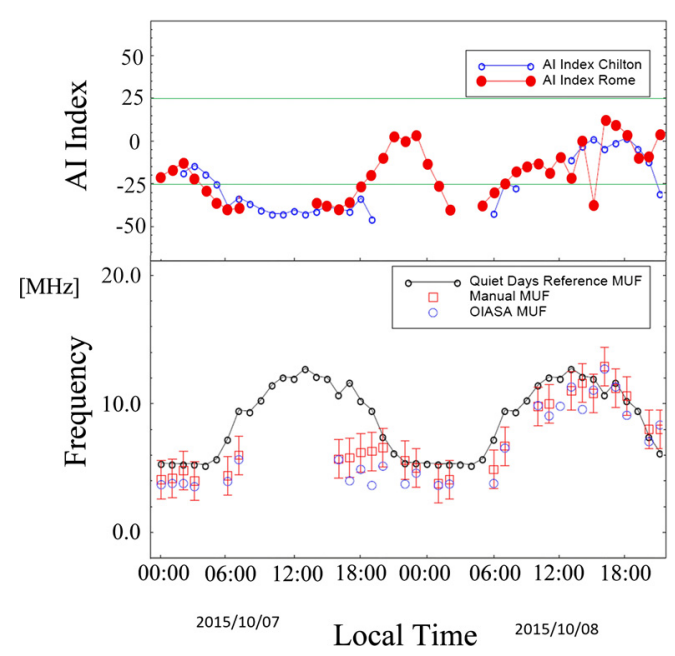

Fig. 6. The plot in the lower panel shows the results of the comparison between automatic scaling and manual scaling of the ionograms recorded on October 7 and 8, 2015. The red open squares indicate the MUF measured by the operator, and the red error bars indicate the range of $\pm 1.5 \mathrm{MHz}$ from the manually scaled MUF. Blue circles indicate the OIASA estimates of the MUF, whose values are considered acceptable if located within the error bars. The black line represents the average manual MUF values, considering a week before and a week after the two ionospheric disturbed days and refers to the quiet-time daily variation. The upper panel depicts the trend of the AI index of the ionospheric stations of Rome and Chilton, recorded in the days considered.

Results of analysis performed by OIASA algorithm for three different seasons, confirm the ability of OIASA to estimate automatically MUF from oblique ionograms in very similar percentages to those reached by an operator. OIASA was able to automatically scale 536 out of $540(99.3 \%)$ of oblique ionograms scaled by human expert for May 2015 campaign, and 326 out of 351 (92.9\%) and 455 out of 491 (92.7\%) for September 2016 and October 2015 campaigns, respectively. These results show the capability of OIASA in scaling ionograms with sufficient information. Moreover, OIASA was able to automatically reject 14 out of $38(36.8 \%)$ of the oblique ionograms discarded by human expert for May 2015 campaign, and 9 out of $9(100 \%)$ and 51 out of 58 (87.9\%) for September 2016 and October 2015 campaigns, respectively. These results also confirm the capabilities of the OIASA algorithm to discard scaling for ionograms that lack sufficient information, similarly to the unscaled ionograms by human expert. The quality of the MUF estimated by OIASA depends on the signal quality of the ionograms analyzed which depends much on the occurrence of Es layers. Indeed, the Es layers might hide partly or totally the signals of $\mathrm{F}$ region echoes (Fig. 2c, i) making difficult to OIASA to find enough points in the ionogram for a good parabola fitting and thus good MUF estimate.

The data set for May 2015, characterized with high occurrence of Es layer, results to $31 \%$ accurate estimation, and $69 \%$ acceptable and $31 \%$ poor estimation of MUF by OIASA. Better quality is obtained for the September 2016 data set which was characterized by low occurrence of Es layers and whose results report 53\% accurate, $88 \%$ acceptable and $12 \%$ poor estimation of MUF. Finally, the data set analyzed for October 2015, characterized by low Es layer occurrence report $47 \%$ accurate, $82 \%$ acceptable and $18 \%$ poor estimation of MUF. We should notice also that OIASA can provide $4 \%$ of wrong MUF estimate depending on the quality of ionograms.

We have evaluated also the performance of the OIASA algorithm to properly estimate effects of geomagnetic storms on ionospheric variation. The geomagnetic storms can cause negative or positive ionospheric effects, uplifting the F2 layer (e.g. Blanch \& Altadill, 2012; Blanch et al., 2013), and/or launching TIDs. Negative ionospheric effects would result in lower MUF for 1F2 compared to $1 \mathrm{E}$ or $1 \mathrm{~F} 1$ (Fig. 2g, h), positive effects may result in having oblique signals beyond ionogram limits (Fig. 2d) and TIDs can generate additional stratification of the ionosphere, omit this making OIASA to fail in estimating the MUF. We have focused on the variation of the MUF as estimated by OIASA for 7-8 October 2015, when an intense geomagnetic storm, according to the criteria of Gonzalez \& Tsurutani (1987), was developed, reaching minimum Dst values below $-110 \mathrm{nT}$. A comparison with the variation of the $\mathrm{AI}$ index, which defines the ionospheric activity conditions, have been done also for these days, taking as reference the stations of Rome and Chilton. The trend of the AI index over these stations has been analyzed in relation to the performance of the autoscaling of the MUF by OIASA algorithm. Results presented in Tables 4 and 5 clearly show that percentage of estimation of the MUF compares very well with that measured by human operator, and quality of auto scaling (over $50 \%$ of accurate and over $80 \%$ of acceptable MUF estimation) is similar to the performance under quiettime intervals (Tab. 2). Besides a very good agreement between the MUF values provided by the software and the ones provided by the operator can be seen from the results. OIASA can also monitor the negative effect on the MUF estimates during the most of the time with disturbed ionospheric conditions (Fig. 6).

Finally, it is worth to remark that since the Ebro ionograms carry both vertical and oblique soundings traces, is difficult to totally filter out the information related to the oblique incidence signal from the vertical incidence signal (Fig. 3). This could introduce some noise which affect the automatic scaling of the oblique traces of the image. Therefore the performance of OIASA would likely improve if applied to ionograms having the oblique traces only.

All together we can conclude that OIASA algorithm is a suitable tool to automatically scale MUF from OI ionograms as well as its usability as a near-real-time tool for ionospheric monitoring purposes, being able to track effects in the ionospheric characteristics caused by space weather events.

Acknowledgments. DA and EB were supported by Universitat Ramon Llull projects 2016-URL-Internac-027 funded by "Obra Social la Caixa", and 2017-URL-Proj-030 funded by "Secretaria d'Universitats i Recerca del Departament d'Empresa i Coneixement de la Generalitat de Catalunya". Authors thank you Mr. Alonso Monstazo (EA3EPH) for his help in scaling OI ionograms. The editor thanks Sergey Fridman and an anonymous referee for their assistance in evaluating this paper. 


\section{References}

Ads AG, Bergadà P, Regué JR, Alsina-Pagès RM, Pijoan JL, Altadill D, Badia D, Graells S. 2015. Vertical and oblique ionospheric soundings over the longhaul HF link between Antarctica and Spain. Radio Sci 50: 916-930. DOI:10.1002/2015RS005773.

Bilitza D, Altadill D, Truhlik V, Shubin V, Galkin I, Reinisch B, Huang X. 2017. International reference ionosphere 2016: from ionospheric climate to real-time weather predictions. Space Weather 15: 418-429. DOI:10.1002/2016SW001593.

Blanch E, Altadill D. 2012. Mid-latitude F-region peak height changes in response to interplanetary magnetic field conditions and modeling results. J Geophys Res 117: A12311. DOI:10.1029/ 2012JA018009.

Blanch E, Marsal S, Segarra A, Torta JM, Altadill D, Curto JJ. 2013. Space weather effects on Earth's environment associated to the 2425 October 2011 geomagnetic storm. Space Weather 11: 153-168. DOI:10.1002/swe.20035.

Breit G, Tuve MA. 1926. A test of the existence of the conducting layer. Phys Rev 28: 554.

Cesaroni C, Scotto C, Ippolito A. 2013. An automatic quality factor for Autoscala foF2 values. Adv Space Res 51: 2316-2321. DOI:10.1016/j.asr.2013.02.009.

Galkin IA, Khmyrov GM, Kozlov AV, Reinisch BW, Huang X, Paznukhov VV. 2008. The ARTIST 5 in radio sounding and plasma physics. AIP Conf Proc 974: 150-159. DOI:10.1063/1.2885024.

Galkin IA, Reinisch BW, Huang X, Bilitza D. 2012. Assimilation of GIRO data into a real-time IRI. Radio Sci 47: RS0L07. DOI:10.1029/2011RS004952.

Gilbert JD, Huang RW. 1988. A comparison between the automatic ionogram scaling system ARTIST and the standard manual method. Radio Sci 23: 968-974. DOI:10.1029/RS023i006p00968.

Gonzalez WD, Tsurutani BT. 1987. Criteria of interplanetaryparameters causing intense magnetic storms (Dst $<100 \mathrm{nT}$ ). Planet Space Sci 35: 1101-1109. DOI:10.1016/0032-0633(87)90015-8.

Hervás M, Alsina-Pagès RM, Orga F, Altadill D, Pijoan JL, Badia D. 2015. Narrowband and wideband channel sounding of an Antarctica to Spain ionospheric radio link. Remote Sens 7: 11712-11730. DOI:10.3390/rs70911712.

Hocke K, Schlegel K. 1996. A review of atmospheric gravity waves and travelling ionospheric disturbances: 1982-1995. Ann Geophys 14: 917-940. DOI:10.1007/s00585-996-0917-6.

Ippolito A, Scotto C, Francis M, Settimi A, Cesaroni C. 2015. Automatic interpretation of oblique ionograms. Adv Space Res $\mathbf{5 5}$ : 1624-1629.
Ippolito A, Scotto C, Sabbagh D, Sgrigna V, Maher P. 2016. A procedure for the reliability improvement of the oblique ionograms automatic scaling algorithm. Radio Sci 51: 454-460. DOI:10.1002/ 2015RS005919.

Mielich J, Bremer J. 2010. A modified index for the description of the ionospheric short- and long-term activity. Ann Geophys 28: 2227 2236. DOI:10.5194/angeo-28-2227-2010.

Pezzopane M, Scotto C. 2007. The automatic scaling of critical frequency foF2 and MUF(3000)F2: a comparison between Autoscala and ARTIST 4.5 on Rome data. Radio Sci 42: RS4003. DOI:10.1029/2006RS003581.

Piggott WR, Rawer K, U.R.S.I. handbook of ionogram interpretation and reduction, Adopted by U.R.S.I. Commission III, Warsaw, Poland, 1972.

Pijoan JL, Altadill D, Torta JM, Alsina-Pagès RM, Marsal S, Badia D. 2014. Remote geophysical observatory in Antarctica with HFdata transmission: a review. Remote Sens 6: 7233-7259. DOI:10.3390/ rs6087233.

Prölss GW, Očko M. 2000. Propagation of upper atmospheric storm effects towards lower latitudes. Adv Space Res 26: 131-135. DOI:10.1016/S0273-1177(99)01039-X.

Reinisch BW, Huang X. 1983. Automatic calculation of electron density profiles from digital ionograms: 3 . Processing of bottomside ionograms. Radio Sci 18: 477-492. DOI:10.1029/ RS018i003p00477.

Reinisch BW, Paznukhov VV, Galkin IA, Altadill D, McElroy J. 2008. Precise radar range measurements with digisondes in radio sounding and plasma physics. AIP Conf Proc 974: 144-149. DOI:10.1063/1.2885022.

Reinisch BW, Galkin IA, Khmyrov GM, Kozlov AV, Bibl K, Lisysyan IA, Cheney GP, Huang X, Kitrosser DF, Paznukhov VV, Luo Y, Jones W, Stelmash S, Hamel R, Grochmal J. 2009. New digisonde for research and monitoring applications. Radio Sci 44: RS0A24. DOI:10.1029/2008RS004115.

Scotto C. 2009. Electron density profile calculation technique for Autoscala ionogram analysis. Adv Space Res 44: 756-766. DOI:10.1016/j.asr.2009.04.037.

Scotto C, Pezzopane M. 2002. A software for automatic scaling of foF2 and MUF(3000)F2 from ionograms. In: Proceedings of URSI 2002, Maastricht, 17-24 August, 2002. http://www.ursi.org/ proceedings/procGA02/papers/p1018.pdf.

Warrington EM, Stocker AJ. 2003. Measurements of the Doppler and multipath spread of the HF signals receivedover a path oriented along the midlatitude trough. Radio Sci 38: 1080. DOI:10.1029/ 2002RS002815.

Cite this article as: Ippolito A, Altadill D, Scotto C, Blanch E. 2018. Oblique ionograms automatic scaling algorithm OIASA application to the ionograms recorded by Ebro observatory ionosonde. J. Space Weather Space Clim. 8: A10 